\title{
A Two-step, Stereoselective Synthesis of Nine- and Ten- Membered Carbocycles from Phthalates
}

\author{
Gustavo Prado, Alberte X. Veiga, Fernando Fernández-Nieto, M. Rita Paleo, * F. Javier Sardina* \\ Departamento de Química Orgánica and Centro Singular de Investigación en Química Biológica y Materiales Mo- \\ leculares (CIQUS), Universidad de Santiago de Compostela, 15782 Santiago de Compostela, SPAIN
}

Supporting Information Placeholder

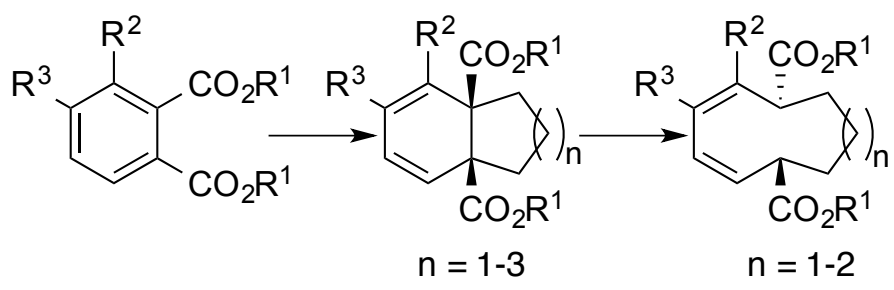

\begin{abstract}
A two-step, stereoselective procedure for the synthesis of nine- and ten-membered carbocycles from readily available phthalates is described. A variety of dialkyl phthalates have been transformed into [6,n]-fused bicyclo systems (n $=5,6,7$ ) by a dearomatization/cyclization process, and then converted into cyclonona- and cyclodecadienes through a bond cleavage reaction, both processes promoted by alkaline metals in THF.
\end{abstract}

The development of practical methods for the synthesis of nine- and ten-membered carbocycles is still challenging. ${ }^{1}$ Despite the different strategies that have been explored for this purpose, such as transition-metal-catalyzed cycloaddition reactions, ${ }^{2}$ fragmentations ${ }^{3}$ and ring expansions, ${ }^{4}$ cyclizations, ${ }^{5}$ ring-closing metathesis, ${ }^{6}$ and oxygenbridge templating approaches, ${ }^{7}$ among others, ${ }^{8}$ there is still a need for developing synthetic methods that provide these molecules in a few steps from readily available starting materials. We report herein our serendipitous discovery of a two-step preparation of nine- and ten-membered carbocycles from inexpensive phthalates, which involves the use of alkali metals in both steps.

We are interested in exploiting dearomatization reactions to build complex structures from inexpensive and readily available aromatic compounds. In this context, we have already reported on a one-step dearomatizationannulation protocol that affords fused bicyclic compounds from the reaction of aromatic diesters with tin nucleophiles, followed by trapping of bis-enolate intermediate species with primary bis-electrophiles. ${ }^{9,10}$ Unfortunately, the synthetic potential of this transformation is diminished by the toxicity and high cost of the required organotin compounds, even though we found conditions to perform the reaction using substoichiometric amounts of tin reagents. ${ }^{9 \mathrm{a}}$ For an unrelated project, we developed the reduction of dimethyl anthracene-9,10-dicarboxylate with lithium/naphthalene under ammonia-free Birch conditions," which generated a stable bis-enolate. Dialkylation of this intermediate gave medium- and large-ring dibenzo[n.2.2] carbobicycles. $^{12}$ By combining the rationales from these two projects, we decided to investigate the possibility of generating bis-enolates from phthalates under reductive conditions, thus avoiding the use of hazardous tin reagents, and to further explore the chemistry of these species, pursuing access to fused bicyclic compounds. We were pleasantly surprised when our studies in this area uncovered, additionally, that these latter compounds underwent a facile bond-cleavage reaction under reductive conditions, to give medium-sized carbocycles. $^{13}$

For the initial investigation on the reductive alkylation, we chose diisopropyl phthalate as the starting aromatic diester, lithium metal as the reductant and 1,3dibromopropane as the electrophile. When an excess of lithium metal in THF was used as the reducing agent, the ensuing reaction was very slow and only low conversions $(15-20 \%)$ to the desired product 2 a were achieved. Sodium proved to be a more efficient reductant than lithium. Thus, when ra was treated with sodium metal in THF for $16 \mathrm{~h}$ at $-78{ }^{\circ} \mathrm{C}$, and the intermediate bis-enolate quenched with 1,3-dibromopropane, the desired bicycle 2 a was isolated in $92 \%$ yield. The cis-stereochemistry of the product was assigned by comparison with the product obtained via stanna-Brook rearrangement. ${ }^{9 \mathrm{~b}}$ Isopropyl esters were the best substrates for this reaction, although methyl (70\% yield) and $t$-butyl ( $85 \%$ yield) esters worked well too (entries 1-3, Table 1).

This reaction tolerates the presence of substituents on the aromatic ring, although at the cost of a considerable rate 
reduction, making it necessary to add naphthalene as an electron carrier to get complete conversions. ${ }^{14}$ The corresponding products $\mathbf{2 d - h}$ were isolated in moderate to good yields (see entries 4 to 8 , Table 1 ). The presence of a methyl group at $\mathrm{C}-3$ causes a significant drop in the yield (2d, 56\%) when compared to its $\mathrm{C}_{-4}$ isomer (2e, $75 \%$ ), probably due to destabilization of the intermediate bisenolate by steric compression. Halogen-substituted phthalates afforded only decomposition products.

Table 1. Synthesis of fused bicyclic systems by reductive alkylation. ${ }^{15}$<smiles>[R17]OC(=O)c1ccc([R])c([R])c1C(=O)O[X]</smiles>

1

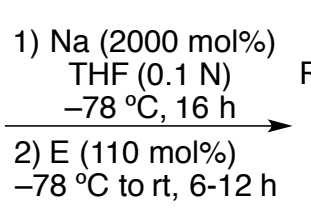
$-78{ }^{\circ} \mathrm{C}$ to rt, $6-12 \mathrm{~h}$

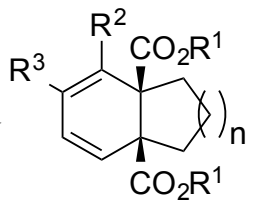

2-4

\begin{tabular}{|c|c|c|c|c|c|c|c|}
\hline entry & $\mathrm{R}^{1}$ & $\mathrm{R}^{2}$ & $\mathrm{R}^{3}$ & $\mathrm{E}$ & \multicolumn{3}{|c|}{$\mathrm{n}$ product yield } \\
\hline 1 & $\operatorname{Pr}$ & $\mathrm{H}$ & $\mathrm{H}$ & $\mathrm{Br}\left(\mathrm{CH}_{2}\right)_{3} \mathrm{Br}$ & 4 & $2 a$ & $92 \%$ \\
\hline 2 & $\mathrm{Me}$ & $\mathrm{H}$ & $\mathrm{H}$ & $\mathrm{Br}\left(\mathrm{CH}_{2}\right)_{3} \mathrm{Br}$ & & $2 b$ & $70 \%$ \\
\hline 3 & $t \mathrm{Bu}$ & $\mathrm{H}$ & $\mathrm{H}$ & $\mathrm{Br}\left(\mathrm{CH}_{2}\right)_{3} \mathrm{Br}$ & & 2c & $85 \%$ \\
\hline 4 & $\operatorname{Pr}$ & $\mathrm{Me}$ & $\mathrm{H}$ & $\mathrm{Br}\left(\mathrm{CH}_{2}\right)_{3} \mathrm{Br}$ & & 2d & $56 \%$ \\
\hline 5 & $\operatorname{Pr}$ & $\mathrm{H}$ & $\mathrm{Me}$ & $\mathrm{Br}\left(\mathrm{CH}_{2}\right)_{3} \mathrm{Br}$ & 1 & $2 e$ & $75 \%$ a \\
\hline 6 & $\mathrm{Me}$ & $\mathrm{H}$ & $\mathrm{OMe}$ & $\mathrm{Br}\left(\mathrm{CH}_{2}\right)_{3} \mathrm{Br}$ & & ff & $55 \% a$ \\
\hline 7 & $\mathrm{Me}$ & $\mathrm{H}$ & $\mathrm{CO}_{2} \mathrm{Me}$ & $\mathrm{Br}\left(\mathrm{CH}_{2}\right)_{3} \mathrm{Br}$ & 1 & $2 g$ & $30 \% a$ \\
\hline 8 & $\operatorname{Pr}$ & $\mathrm{H}$ & $\mathrm{CO}_{2} / \mathrm{Pr}$ & $\mathrm{Br}\left(\mathrm{CH}_{2}\right)_{3} \mathrm{Br}$ & T & h & $48 \% a$ \\
\hline 9 & $\operatorname{Pr}$ & $\mathrm{H}$ & $\mathrm{H}$ & $\mathrm{H}_{2} \mathrm{C}=\mathrm{C}\left(\mathrm{CH}_{2} \mathrm{Cl}\right)_{2}$ & & $2 \mathbf{i}$ & $60 \%$ b \\
\hline 10 & $\operatorname{Pr}$ & $\mathrm{H}$ & $\mathrm{H}$ & $\mathrm{Br}\left(\mathrm{CH}_{2}\right)_{4} \mathrm{Br}$ & 2 & a & $88 \%$ \\
\hline 11 & $t \mathrm{Bu}$ & $\mathrm{H}$ & $\mathrm{H}$ & $\mathrm{Br}\left(\mathrm{CH}_{2}\right)_{4} \mathrm{Br}$ & 2 & b & $87 \%$ \\
\hline 12 & $\operatorname{Pr}$ & $\mathrm{H}$ & $\mathrm{H}$ & - & & c & $55 \%$ \\
\hline 13 & $\operatorname{Pr}$ & $\mathrm{H}$ & $\mathrm{H}$ & lene- $\alpha, \alpha^{\prime}$-diO & & $3 d$ & $48 \%$ \\
\hline 14 & $\operatorname{Pr}$ & $\mathrm{H}$ & $\mathrm{H}$ & $\mathrm{I}\left(\mathrm{CH}_{2}\right)_{5} \mathrm{I}$ & 3 & $4 a$ & $76 \%$ \\
\hline
\end{tabular}

a 1) $\mathrm{Na}(1000 \mathrm{~mol} \%)$, naphthalene (60 mol\%), $-50^{\circ} \mathrm{C}, 6 \mathrm{~h}$ 2) $\mathrm{E}(110 \mathrm{~mol}),-50^{\circ} \mathrm{C}$ to $\mathrm{rt}, 12-16 \mathrm{~h}$

${ }^{b} \mathrm{E}$ dissolved in $\operatorname{DMF}(0.55 \mathrm{M}),-78^{\circ} \mathrm{C}$ to rt, $24 \mathrm{~h}$<smiles>C=C1CC2(C(=O)OCC)C=CC=CC2(C(=O)OCC)C1</smiles>

2i<smiles>CCCC1(C(=O)OCC)C=CC=CC1(C(=O)OCC)C(=O)OCC</smiles>

$3 c$<smiles>CCCC1(C(=O)OCC)C=CC=CC1(C(=O)OCC)C(=O)OCC</smiles>

3d
Variations in the nature and the length of the chain of the bis-electrophile were also well tolerated. Thus, the exomethylene bicyclo[4.3.o]nonane $2 \mathbf{i}$ was easily prepared in $60 \%$ yield when 3-chloro-2-chloromethyl-1-propene was used as the electrophile. Functionalized and unfunctionalized bicyclo[4.4.0]decadienes 3 and bicyclo[5.4.o]undecadienes 4 were also prepared in good yields (entries 10-14, Table 1). Remarkably, the cyclization to a seven membered ring occurred uneventfully, provided that the temperature of the reaction mixture was allowed to reach $35^{\circ} \mathrm{C}$. Thus, bicyclo[5.4.o]undecadiene $4 \mathbf{a}$ was isolated in $75 \%$ yield when using 1,5 -diiodopentane as the electrophile. These results confirm that the reductive alkylation of phthalates is a general process that allows for the preparation of a variety of $[6,5]-[6,6]-$ and $[7,6]-$ fused bicycles using a reducing agent, sodium or sodium/naphthalene, and a suitable bis-electrophile.

With an ample supply of fused bicycles 2-4, we decided to explore their use in the preparation of propellane structures. For our first foray into these type of transformations we explored the acyloin condensation of the ester groups of bicyclo[4.3.0]nonane 2a. But to our surprise and delight, when $2 \mathbf{a}$ was treated with $\mathrm{Li} /$ naphthalene in THF at $-30{ }^{\circ} \mathrm{C}$, we isolated a mixture of cyclononadienes $5 \mathrm{a}$ and 6 and none of the expected acyloin products, after quenching with $\mathrm{iPrOH}$. We surmised that the $\mathrm{C}-\mathrm{C}$ bond of the vicinal diesters of bicyclo[4.3.o]nonane $2 \mathrm{a}$ had been reductively cleaved to give a nine-membered bis-enolate, which then had been doubly protonated upon quenching of the reaction, affording a mixture of kinetic and thermodynamic protonation products. There are precedents for this kind of reductive cleavage of 1,2 -diesters, ${ }^{13}$ but the mechanistic picture of this reaction and, especially, the involvement of enolate intermediates has not been studied.

Scheme 1. Regioselective ring-opening reaction.

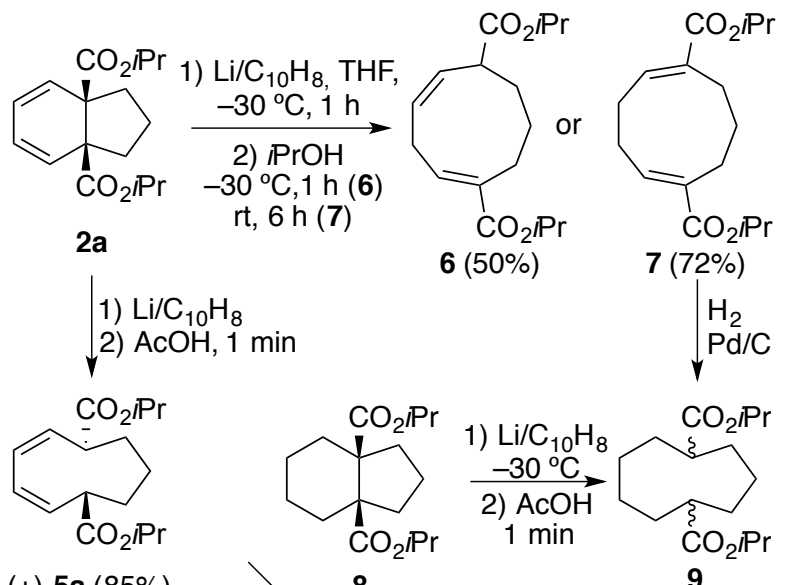

$( \pm)-5 a(85 \%)$
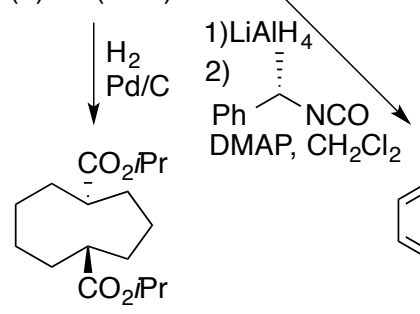

$(55: 45,62 \%$ from 8$)$

(40:60, 98\% from 7)

trans- $( \pm)-9(99 \%)$

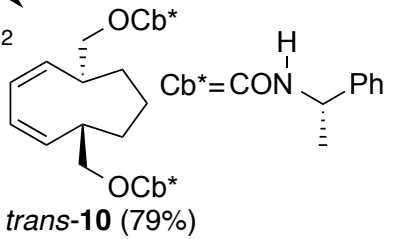

If a bis-enolate, most probably formed by bond-cleavage of a dianion diradical (a diketyl) species, ${ }^{13 \mathrm{a}}$ is an intermediate in this transformation, then choosing the right protonation conditions should allow us to obtain selectively products of protonation under kinetic or thermodynamic conditions. In fact, after some experimentation, we found optimized conditions for the selective preparation of cyclononadienes 5a, 6 and 7 (Scheme 1). Unconjugated cyclononadiene 5a was obtained in excellent yield (85\%) when the reaction was quenched with $\mathrm{AcOH}$ at $-30^{\circ} \mathrm{C}$ for just $1 \mathrm{~min}$. In contrast, quenching the reaction with 
$i \mathrm{PrOH}\left(\mathrm{h}\right.$ at $-30{ }^{\circ} \mathrm{C}$ ) gave solely mono-conjugated cyclononadiene 6 (50\% yield). Moreover, when the reaction was quenched with $i \mathrm{PrOH}$ at $-30{ }^{\circ} \mathrm{C}$ and then stirred for 6 $\mathrm{h}$ at RT, the doubly conjugated cyclononadiene 7 was isolated as the single reaction product ( $72 \%$ yield).

Remarkably, this cleavage-protonation reaction of bicyclic dienes 2 proceeds with complete stereoselection, as established by the comparison of the ${ }^{13} \mathrm{C}-\mathrm{NMR}$ spectrum of the hydrogenation product of 5 a (which showed signals for only one stereoisomer), with that of the ring-opening product of the saturated hydrindane $\mathbf{8}$ (which gave a 55:45 mixture of diastereomers of $\mathbf{9}$, readily distinguishable by $\left.{ }^{13} \mathrm{C}-\mathrm{NMR}\right)$, and that of the hydrogenation product of bisunsaturated diester 7 , which also afforded a mixture of diasteroisomers of $\mathbf{9}$ (Scheme 1). To figure out the relative stererochemistry of the stereogenic centers of diene $5^{\mathbf{a}}$, we transformed it into a crystalline derivative by a twostep procedure: $\mathrm{LiAlH}_{4}$ reduction of $5 \mathbf{a}$ to the corresponding diol and its subsequent derivatization with $(S)-(-)-\alpha-$ methylbenzyl isocyanate and DMAP in $\mathrm{CH}_{2} \mathrm{Cl}_{2}$ (79\% yield, 2 steps). X-ray crystallographic analysis of carbamate $\mathbf{1 0}$ showed a trans disposition of the side chains. ${ }^{16}$

Scheme 2. Stereoselective ring-opening/alkylation.

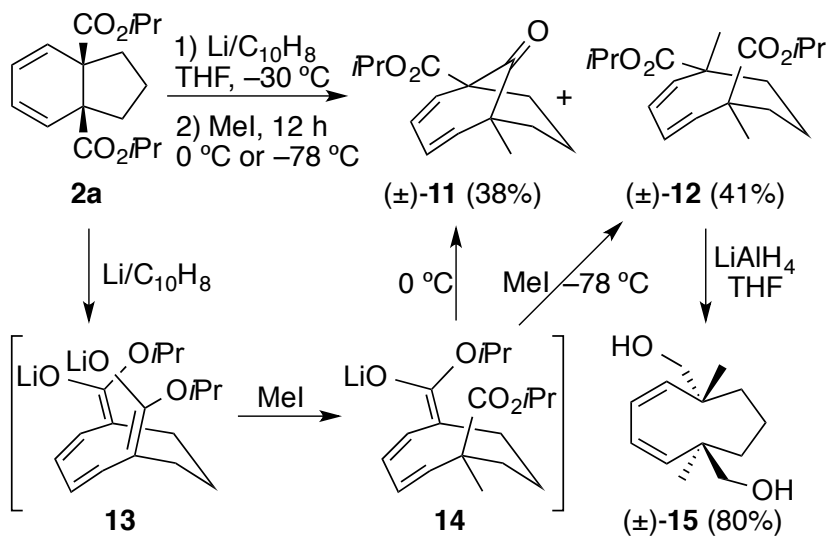

If the ring-opening reaction indeed takes place to give a bis-enolate intermediate that then undergoes stereoselectively protonation, then chances are that it could also be stereoselectively alkylated with an appropriate electrophile. In fact, when we treated bicycle 2 a with $\mathrm{Li} /$ naphthalene in THF at $-30{ }^{\circ} \mathrm{C}$ and then trapped the intermediate with methyl iodide, a 1:1 mixture of compounds 11 and 12 (Scheme 2) was formed. Both products are derived from the mono-alkylation of the intermediate bis-enolate 13, to give monoenolate 14, which can then evolve through a Dieckmann condensation to give bicyclo 11, or through a further methylation to yield nonadiene $\mathbf{1 2}$. The selectivity of the reaction could be somewhat steered by changing the reaction temperature: when the reaction was run at $-78^{\circ} \mathrm{C}$ dimethylcyclononene 12 was the major product (6:1 ratio of $\mathbf{1 2}$ and $\mathbf{1 1}$ ), while at $\mathrm{o}{ }^{\circ} \mathrm{C}$ bicyclic 11 was the preferred product ( $4: 1$ ratio of $\mathbf{1 1}$ and $\mathbf{1 2}$ ). The relative configuration of the stereogenic centers of 12 was determined to be trans by X-ray diffraction analysis of diol 15, obtained by $\mathrm{LiAlH}_{4}$ reduction of $12(80 \%)$.
To delineate the scope of the stereoselective ringcleavage-protonation sequence, the optimized reaction conditions for the synthesis of kinetic cyclononadiene $5^{\mathbf{a}}$ were applied to several bicyclic dienes (2-3) (Scheme 3). The main conclusions of this study are: (i) the reaction tolerates different esters, but the $i$-propyl ( $85 \%$ yield) is more convenient than the methyl $(52 \%)$ or $t$-butyl $(78 \%)$ groups; (ii) the presence of a methyl substituent in the cyclohexadiene ring causes a drop in yield $(\mathbf{5} \mathbf{d}$ and $\mathbf{5 e}$ were isolated in 53 and 50\% yields, respectively); and (iii) the presence of an exo methylene in the 5-membered ring does not interfere with the bond cleavage, (5i was obtained in $55 \%$ yield, similarly to other unsaturated substrates, such as $\mathbf{1 7}$ and $\mathbf{1 8}$ ).

Scheme 3. Stereoselective reductive ring-opening to 9- and 10-membered carbocycles.

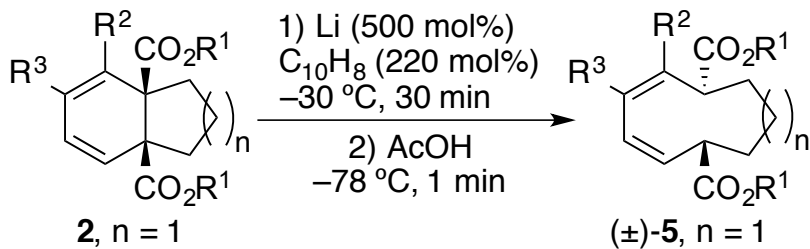
$3, n=2$
$( \pm)-16-18, n=2$
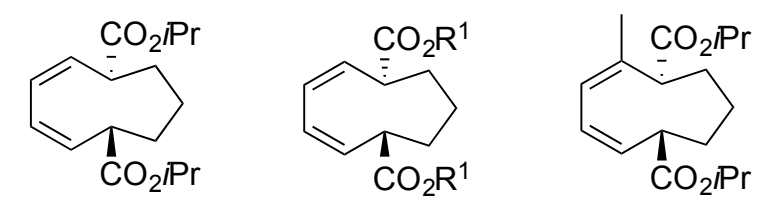

$5 a, 85 \%$

5b, $R^{1}=M e, 52 \%$

$5 d, 53 \%$<smiles>CC1=CCCCC(CC(=O)OC(C)C)(C(=O)OC(C)C)CC1</smiles>

5c, $R^{1}=t B u, 78 \%$

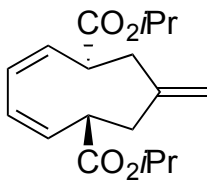

$5 e, 50 \%$<smiles>CCCCCC(C(=O)OCC)C(CCCC)C(=O)OCC</smiles>

$16,52 \%$<smiles>COC1=C/[C@H](C(C)=O)CCCC[C@@H](OC)/C=C\1</smiles>

$5 f, 69 \%$

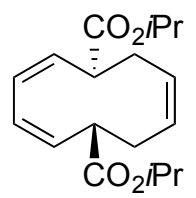

$17,57 \%$

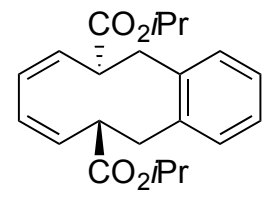

$18,54 \%$

The bond cleavage reaction is not limited to the bicyclo[4.3.0]nonanes, as 10-membered carbocyclic dienes could also be prepared from 6,6-fused bicycles (Scheme 3). Thus, when bicycle $\mathbf{3}^{\mathbf{a}}$ was treated with lithium/naphthalene at $\mathrm{o}{ }^{\circ} \mathrm{C}$ for $1 \mathrm{~h}$, and then quenched with $\mathrm{AcOH}$ for $1 \mathrm{~min}$ at the same temperature, cyclodecadiene 16 was isolated in $52 \%$ yield as the sole reaction product. A similar result was obtained from bicyclic compound possessing further unsaturation (3c led to cyclodecatriene $\mathbf{1 7}$ in $57 \%$ yield) or substitution (which allowed the preparation of $\mathbf{1 8}$ from $3 \mathbf{d}$ in $54 \%$ yield). Unfortunately all attemps to prepare 11-membered ring dienes starting from the corresponding bicyclo[5.4.o]undecadiene 4 a have been unsuccessful to date. 
In an attempt to gain mechanistic insights into this transformation and to pinpoint which are the precise structural requirements for the ring-opening reaction to be successful, a series of diesters (see Scheme 4) were treated with $\mathrm{Li} /$ naphthalene, followed by protonation with acetic acid. Cyclohexadiene diesters (cis-19, trans-19, cis-2o, and trans-2o, all reacted separately) were successfully opened (to give $\mathbf{2 1}$ or 22) in similar yields, showing that the cleavage is not sensitive to stereoelectronic effects. In stark contrast, no ring-opened product was observed from saturated diisopropyl cyclohexane-1,2-dicarboxylates $\mathbf{2 5}$. Thus, the stability of the intermediate bis-enolate seems to be the determining factor in the success of the reaction. The unconjugated, less stable bis-enolate which should be formed from the saturated esters 25 appears to be inaccessible under our reaction conditions.

Scheme 4. Scope of substrates for ring-opening reactions.

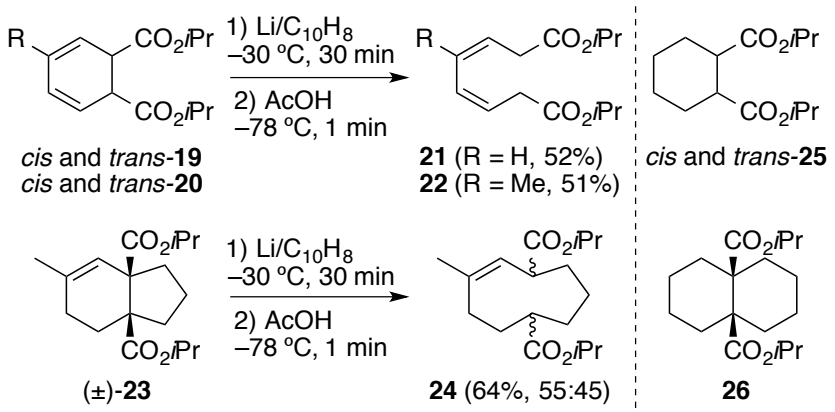

Strain release also appears to play a role in facilitating the bond cleavage, as mono-unsaturated and saturated bicyclic 6,5-fused systems 23 and $\mathbf{8}$ also underwent cleavage (to 24 and 9, respectively, isolated as 55:45 stereoisomeric mixtures), but the less strained saturated 6,6-bicyclic compound $\mathbf{2 6}$ did not.

In summary, we have developed a straightforward, twostep, stereoselective synthesis of functionalized nine- and ten-membered carbocycles from phthalates, mediated by alkali metals. Further studies to understand and exploit the stereoselectivity of the ring opening process are currently in progress.

\section{ASSOCIATED CONTENT}

\section{Supporting Information}

Experimental procedures and characterization data for all new compounds, and X-ray crystallographic data of compounds 10 and 15. This material is available free of charge via the Internet at http://pubs.acs.org.

\section{AUTHOR INFORMATION}

\section{Corresponding Authors}

*E-mail: rita.paleo@usc.es

*E-mail: javier.sardina@usc.es

\section{Notes}

The authors declare no competing financial interest.
This work was supported by the Spanish MINECO (CTQ201122436), and the Xunta de Galicia (GRC2014/o29).

\section{REFERENCES}

(1) (a) Yet, L. Chem. Rev. 2000, 100, 2963-3007. (b) Yet, L. Tetrahedron, 1999, 55, 9349-9403.

(2) (a) Yamasaki, R.; Ohashi, M.; Maeda, K.; Kitamura, T.: Nakagawa, M.; Kato, K.; Fujita, T.; Kamura, R.; Kinoshita, K.; Masu, H.; Azumaya, I.; Ogoshi, S.; Saito, S. Chem. Eur. J. 2013, 19, 3415-3425. (b) Saito, S.; Maeda, K.; Yamasaki, R.; Kitamura, T.; Nakagawa, M.; Kato, K.; Azumaya, I.; Masu, H. Angew. Chem. Int. Ed. 2010, 49, 1830-1833. (c) Murakami, M.; Itami, K.; Ito, Y. Angew. Chem. Int. Ed. 1998, 37, 3418-3420.

(3) (a) Drahl, M. A.; Manpadi, M.; Williams, L. J. Angew. Chem. Int. Ed. 2013, 52, 11222-11251. (b) Weyerstahl, P.; Marschall, H. In Comprehensive Organic Synthesis; Trost, B. M., Fleming, I., Eds.; Pergamon Press: Oxford, 1991; Vol 6, pp 1041-1070. (c) Prantz, K.; Mulzer, J. Chem. Rev. 2010, 110, 3741-3766.

(4) (a) Tummatorn, J.; Dudley, G. B. Org. Lett. 2011, 13, 15721575. (b) Xu, W.; Zou, J.-P.; Mu, X.-J.; Zhang, W. Tetrahedron Lett 2008, 49, 7311-7314. (c) Li, C.-J.; Chen, D.-L.; Lu, Y.-Q.; Haberman, J. X.; Mague, J. T. J. Am. Chem. Soc. 1996, 118, 4216-4217.

(5) (a) Saadi, J.; Lentz, D.; Reissig, H.-U. Org. Lett. 2009, 11, 3334-3337. (b) Deiters, A.; Fröhlich, R.; Hoppe, D. Angew. Chem. Int. Ed. 200o, 39, 2105-2107. (c) Illuminati, G.; Mandolini, L. Acc. Chem. Res. 1981, 14, 95-102. (d) Denmark, S. E.; Yang, S.-M. Tetrahedron, 2004, 6o, 9695-9708. (e) Ma, S.; Negishi, E. J. Am. Chem. Soc. 1995, 117, 6345-6357.

(6) (a) Hamel, C.; Prusov, E. V.; Gertsch, J.; Schweizer, W. B.; Altmann, K.-H. Angew. Chem. Int. Ed. 2008, 47, 10081-10085. (b) Paley, R. S.; Estroff, L. A.; Gauguet, J.-M.; Hunt, D. K.; Newlin, R. C. Org. Lett. 200o, 2, 365-368. (c) Castoldi, D.; Caggiano, L.; Bayón, P.; Costa, A. M.; Cappella, P.; Sharon, O.; Gennarim, C. Tetrahedron 2005, 61, 2123-2139. (d) Maier, M. E. Angew. Chem. Int. Ed. 20oo, 39, 2073-2077. (e) Lejkowski, M.; Gais, H.-J.; Banerjee, P.; Vermeeren, C. J. Am. Chem. Soc. 2006, 128, 1537815379.

(7) (a) López, F.; Mascareñas, J. L. Chem. Eur. J. 2007, 13, 21722178. (b) López, F.; Castedo, L.; Mascareñas, J. L. Org. Lett. 2005, 7, 287-29o. (c) López, F.; Castedo, L.; Mascareñas, J. L. J. Am. Chem. Soc. 2002, 124, 4218-4219. (d) Molander, G. A.; Brown, G. A.; Storch de Gracia, I. J. Org. Chem. 2oo2, 67, 3459-3463. (e) Molander, G. A.; Machouhi, F. J. Org. Chem. 1999, 64, 4119-4123. (f) Molander, G. A.; Köllner, C. J. Org. Chem. 2ooo, 65, 83338339 .

(8) (a) Itoh, Y.; Tsuji, H.; Yamagata, K.; Endo, K.; Tanaka, I.; Nakamura, M.; Nakamura, E. J. Am. Chem. Soc. 2008, 130, 1716117167. (b) Rodríguez, J. R.; Castedo, L.; Mascareñas, J. L. Chem. Eur. J. 2002, 8, 2923-2930.

(9) (a) Pérez-Vázquez, J.; Veiga, A. X.; Prado, G.; Sardina, F. J.; Paleo, M. R. Eur. J. Org. Chem. 2012, 975-987. (b) Monje, P.; Graña, P.; Paleo, M. R.; Sardina, F. J. Org. Lett. 2oo6, 8, 951-954.

(10) Paleo, M. R.; Calaza, M. I.; Graña, P.; Sardina, F. J. Org. Lett. 2004, 6, 1061-1063.

(11) (a) Donohoe, T. J.; Harji, R. R.; Cousins, R. P. C. Tetrahedron Lett. 200o, 41, 1327-1330. (b) Donohoe, T. J.; Harji, R. R.; Cousins, R. P. C. Tetrahedron Lett. 200o, 41, 1331-1334. (c) Donohoe, T. J.; Raoof, A.; Linney, I. D.; Helliwell, M. Org. Lett. 2001, 3, 861-864.

(12) Lobato, R.; Veiga, A. X.; Pérez-Vázquez, J.; FernándezNieto, F.; Paleo, M. R.; Sardina, F. J. Org. Lett. 2013, 15, 40904093 .

(13) (a) Bloomfield, J. J.; Owsley, D. C.; Ainsworth, C.; Robertson, R. E. J. Org. Chem. 1975, 40, 393-402. (b) Bloomfield, J. J.; Martin, R. A.; Nelke, J. M. J. Chem. Soc., Chem. Commun. 1972, 96-97. (c) Warner, P. M.; Chen, B.-L.; Wada, E. J. Org. Chem.

\section{ACKNOWLEDGMENT}


1981, 46, 4795-4797. (d) Gassman, P. G.; Creary, X. J. Chem. Soc., Chem. Commun. 1972, 1214-1215. (e) Saha, G.; Bhattacharya, A.; Saha Roy, S.; Ghosh, S. Tetrahedron Lett. 1990, 31, 1483-1484. (f) Saha, G.; Karpha, A.; Saha Roy, S.; Ghosh, S. J. Chem. Soc., Perkin Trans I 1992, 1587-1591.
(14) Ramón, D. J.; Yus, M. Eur. J. Org. Chem. 200o, 225-237.

(15) The use of mesylates affords similar yields to bromides.

(16) The two trans diastereomers displayed only one set of signals in the ${ }^{1} \mathrm{H}$ and ${ }^{13} \mathrm{C}$ NMR spectra. 